\title{
Reciprocal Mentorship as Trans-Systemic Knowledge: A Story of an Indigenous Student and a Non-Indigenous Academic Supervisor Navigating Graduate Research in a Canadian University
}

\author{
Christine Webster, Kathy Bishop
}

\begin{abstract}
Авstract Reciprocal mentorship is how Indigenous students and non-Indigenous supervisors can supportively navigate their way through graduate research in higher education. Reciprocal mentorship as trans-systemic knowledge values both Indigenous and Eurocentric worldviews, whereby the student has the expertise from Indigenous community and the academic supervisor has the expertise in the academic world. Through sharing stories of their research journey within a Canadian University, Webster and Bishop offer key insights around engaging in reciprocal mentorship, navigating the two-worlds, finding a common language, and having shared values. As a result, Indigenous and non-Indigenous students and supervisors may see themselves within the stories and seek reciprocal mentorship to be successful in the academic research and educational journey and make an impact in their university and beyond.
\end{abstract}

KeyWords Reciprocal mentorship, Indigenous-non-Indigenous relationships, higher education, trans-systemic knowledge

Indigenous students' perception of schools, and post-secondary education in particular, may be marred by the history of residential schools in Canada. The Truth and Reconciliation Commission (2015) report stated, "Canada separated children from their parents, sending them to residential schools. This was done not to educate them, but primarily to break their link to their culture and identity" (p. 2). Separation of children from families created intergenerational trauma that is still felt and experienced to this day by many Indigenous peoples, and in the experiences of many Indigenous students in post-secondary institutions. However, as noted by Battiste (2014), an Indigenous renaissance is occurring.

In the Indigenous renaissance, trans-systemic knowledge displaces Eurocentrism and "suggests sites of emerging change and innovation that come from Indigenous peoples animating Indigenous Knowledge (IK), as well as from Eurocentric scholars and students actualizing social justice and the human rights of Indigenous people in the academy and in schools" (Battiste, 2014, p. 84). Much work has been done on a national policy level and establishing distinct Indigenous educational spaces within higher education. As a way to further reclaim 
"Indigenous voice, vision, and knowledge within the Eurocentric worldview and institution" (p. 90), a third space, as noted by Cajete (as cited in Marker, 2016), may now be possible.

This article suggests that this third space can be found in reciprocal mentorship relationships between Indigenous students and non-Indigenous supervisors when they navigate their way through graduate research in higher education. Mentorship has various ways of being enacted. In the Western world, mentorship traditionally has focused on a senior person guiding someone junior for purposes of career advancement (Kram, 1985); whereas, reverse mentorship (Kram \& Hall, 1997) involves a younger person coaching someone older on emergent changes such as technology practices and digital literacy. Reciprocal mentorship posits that mentoring has mutual benefits and responsibilities by both parties (Bessette, 2015; Ferguson, 2017; Harvey et al., 2009). From an Indigenous perspective, mentorship is an essential process in the transmission of knowledge from one generation to the next (Archibald, 2008; Battiste, 2010; Kovach, 2009; Liang \& Peters-Hawkins, 2017; McLeod, 2012; Ndaba, 2013; Tippeconnic Fox, 2009; Thomas, 2018). Leaning on this process-based practice in a Western environment while engaging in the academic research journey can assist with whole-person learning: intellectual, emotional, physical and spiritual (Archibald, 2008; Battiste, 2010; Pidgeon et al., 2014) that is critical to Indigenous peoples. However, in this third space, it is not only about the Indigenous student being mentored, but also the academic supervisor. The supervisor brings expertise within the academy, and the Indigenous student brings expertise from their community. Both bring their lived experience and knowledge as whole people to the learning process.

In 2018, a reciprocal mentorship relationship was formed between the authors. Indigenous student, Christine, and academic supervisor, Kathy, embarked on an exciting dual research project to understand how to enhance the overall learning experience for Indigenous students at Royals Road University in British Columbia, Canada. The dual research project findings paralleled some of our own untold research story. The story we share now is that of the reciprocal mentorship relationship between the Indigenous student and the non-Indigenous academic supervisor navigating our unique academic journey. We offer key insights around reciprocal mentorship through our stories, navigating the two-worlds, finding a common language, and having shared values. We conclude by offering considerations for moving forward on the journey.

\section{Our Story}

A primary way of knowledge transmission by the Nuu-chah-nulth, as within many Indigenous traditions, is through storytelling (Atleo, 2004). McLeod (2012) noted, "the Saulteaux Cree learning system handed down leadership information, knowledge, techniques, and insight from one generation to the next through storytelling" (p. 18). Storytelling can come in many forms, ranging from speaking to lived experiences metaphorically to recounting particular events to reveal life lessons. Recognizing the impact of people sharing their stories, we value the power of storytelling for truth-telling to promote understanding with the potential to evoke change. Smith (2012) shared, "Indigenous peoples want to tell our own stories, write our own versions, in our own ways, for our own purposes" (p. 29). 
Furthermore, Pete (2016) counseled faculty to "tell your stories" (p. 87) as one of a hundred ways to Indigenize and decolonize academic programs and courses. Part of storying is to locate the self (Kovach, 2009). Similarly, in qualitative academic research, researchers position themselves (Glesne, 2016; Saldana \& Omasta, 2018). We recognize that different worldviews exist with subsequent ontologies and epistemologies between Indigenous and Eurocentric ways of being, doing, and relating. As a point of intersection, we begin our story by positioning ourselves with the intention of both introductions of selves and our relationships to the research.

\section{Author Positioning Christine Webster}

My ancestral name is tupał?aqsa, which was given to me by my grandmother. It means woman of the ocean, akin to a mermaid. My name is also Christine, and I am a Nuu-chah-nulth woman from the Ahousaht Nation. Located on the West Coast of Vancouver Island, Ahousaht is a remote community accessed mainly by boat. My grandparents, Andrew and Sarah Webster, raised me in Victoria, British Columbia, the traditional territories of the Coast and Straits Salish peoples. Access to education was the guise for this living arrangement; however, my grandparents gifted much more as they instilled in me strong Nuu-chah-nulth values.

In 2019, I completed my master's degree at Royal Roads University and immediately transitioned into my current doctoral studies at the University of Victoria. Western education has always been encouraged and supported in our family, particularly by my grandparents. To my knowledge, I am the first in my family to receive a master's degree. Choosing a path of education, I hope to inspire others in my family and my community to see higher education as a viable pathway to life-long learning.

\section{Kathy Bishop}

My name is Kathy Bishop. I am an academic supervisor, associate professor, and MA Leadership program head at Royal Roads University. I received my $\mathrm{PhD}$ in Interdisciplinary Studies in 2015. I am a woman of Scottish and European descent. My paternal grandparents immigrated to Canada when they were children. I was raised in North Vancouver, on the lands of the Coast Salish peoples, specifically the Squamish Nation's traditional territory. I followed in my brother's footsteps by going to university.

Along with my aunt, we were the first three in our ancestral family to complete a degree. I am the only one with a $\mathrm{PhD}$.

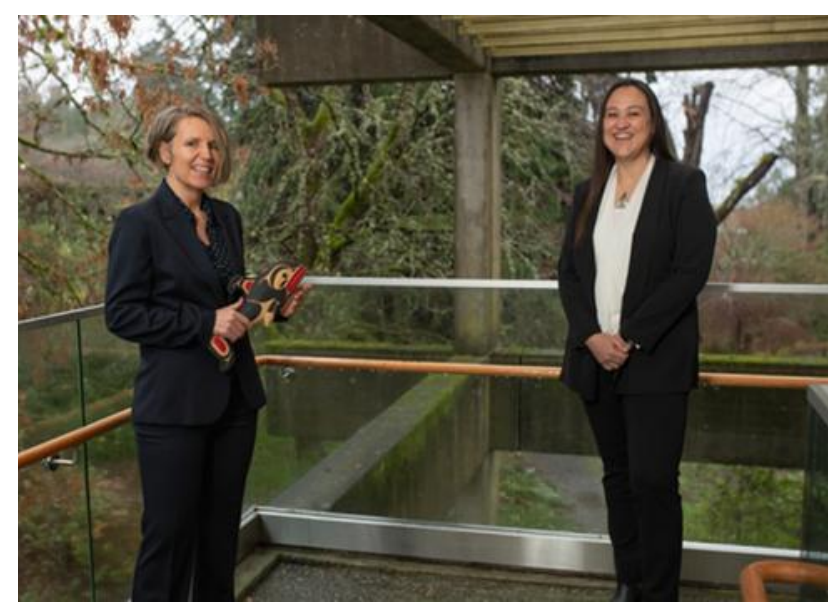

Figure 1. Kathy Bishop and Christine Webster enjoy a conversation about a Coast Salish carving (carver: Howard LaFortune, Jr.) gifted on the grounds of Royal Roads University. Photo credit: Dan Anthon 
Higher education was a substantial value for my father, who never finished high school. Despite this, he rose to a senior-level leadership position in an international insurance company, moving beyond his working-class roots. Both my sons, and three of my nieces and one of my nephews have now attended university. I am deeply committed to being in the service of learning and leadership to make the world a better place.

\section{Research Positioning}

In 2018, Christine and Kathy undertook a dual research project. In conjunction with an inquiry team consisting of co-researchers, the Indigenous Education and Student Support office, and The Heron People Elders group, we sought to understand how the overall learning experience for Indigenous students could be enhanced at Royal Roads University. The project simultaneously included the Indigenous Alumni Survey (IAS) (Webster et al., 2019) project and Traversing Culture and Academy (Webster, 2019). However, the dual research project did not start that way. It evolved through internal university funding received by Kathy and her colleagues, Drs. Elizabeth Hartney and Wanda Krause. These funds were to hire an assistant to conduct the research, and merged as Christine and Kathy worked together as thesis student and academic supervisor.

When the IAS study was funded, Kathy sent a call for expression of interest to all students, Indigenous and non-Indigenous, in the program that she was working with inviting anyone to respond if they were interested in being on the project as a research assistant. Although Kathy knew Christine would be a strong candidate, she posted the call to the whole cohort to allow everyone an opportunity to apply. She did this for purposes of transparency. Kathy also did not want Christine or any other student interested to feel compelled if asked directly to participate by their faculty advisor and program head.

Christine recalls one of the first meetings to discuss the potential of this collaboration. The research journey itself was intimidating for her, let alone considering a partnership. The one thing she felt confident about, however, was her personal experience being an Indigenous student. Preparing herself, she walked into the meeting with the intention to listen to the potential of the collaboration and to not be afraid to share her thoughts.

For this meeting, Kathy was conscious of the inherent power dynamics of being a white professor within a Eurocentric university context. Although Kathy held strong beliefs in equality, agency, and a universal life force connecting all life, she also was aware of the reality of operating in structures privileging hegemony and power. Kathy sought to create a space where she and Christine could each speak their truth. She recognized her privilege to take the lead to set this space. Kathy sought to listen to Christine deeply. She appreciated Christine's willingness to risk speaking her feelings and concerns. Kathy believed that Christine would bring much wisdom, experience and commitment to the project.

Kathy hoped that Christine would make the decision that was best for Christine. Christine and Kathy's willingness to listen, speak their truth and create a space for truly sharing formed some of the strong roots of the reciprocal mentorship relationship. 


\section{Reciprocal Mentorship}

Linking reciprocal mentorship with developing cultural intelligence, Desai et al. (2018) identified that reciprocal mentoring

is relationship-oriented and the cultural differences of the participants can introduce a complexity in this relationship. The success of this relationship is subject to the following assumptions: mutual interest and engagement of the participants; mutual trust and respect; willingness to engage in a discussion related to culture, religion, race, ethnicity, etc.; and commitment to rise above the cultural differences and succeed. (p. 39)

For Christine and Kathy, these assumptions underpinned their work together. As a graduate student, Christine looked to Kathy for mentorship in academic processes, particularly research processes. Tippeconnic Fox (2009) noted that having a "support network of fellow students, friends, professors, mentors, advisors, and Indian organizations, groups or centers" (p. 74) contributed to the success of Indigenous students. Although the student performs graduate research, academic supervisors can provide valuable guidance on how to proceed. Among many examples, we share the challenge of utilizing a conventional method within Indigenous methodology; Christine considered the appropriateness of the online survey. She struggled with how an online survey could be conducted while staying true to Nuu-chah-nulth protocols and practices. Nuu-chah-nulth peoples are an oral people, with critical business normally taken care of face-to-face. Christine was able to make new meaning about the use of the online survey by reading the works of other Indigenous scholars. She was reminded of the Nuu-chahnulth practice of storytelling exemplified in the work of Atleo (2004), whereby he shared origin stories, typically told orally, in written form. Archibald (2008) offered a perspective that "oral tradition still lives, and the written tradition is growing within it" (p. 13) and that "storytellers use their personal life experiences as teaching stories in a manner similar to how they use traditional stories" (p. 112). Recognizing that the intention was to learn about Indigenous student experiences of their post-secondary educational journey, Christine now felt that asking Indigenous students to share their student experience in written form through the online survey could be a suitable method within the methodology. Kathy supported this process, and the time it took for Christine to frame it in a way that felt like the work was being done with a good mind and a good heart. Kathy's support came in the ways of listening to Christine's story, struggles and ideas, and being curious, asking questions respectfully about practice and protocols, and offering insights into Western practice of similar methods to identify the similarities and differences. As the academic supervisor, Kathy provided Christine with enough guidance so that Christine could make sense of completing the work in a meaningful way from an Indigenous perspective.

Although Kathy provided Christine mentorship, Christine also supported Kathy. As an Indigenous woman, Christine believed mentorship to be a responsibility, not only with her supervisor but beyond. Thomas' (2018) work focused on Indigenous women in leadership and 
described how Indigenous women have roles and responsibilities related to being "carriers of culture" (p. 13) and are the teachers who lead by role-modelling. By engaging in the work of improving relationships between the university community and Indigenous students through the dual research project, Christine was accepting the responsibility to acquire skills to be able to offer mentorship to future Indigenous students of higher education and to share knowledge with non-Indigenous instructors to enhance understanding of the barriers Indigenous students face. Christine's sharing of knowledge with Kathy contributed to the reciprocal nature of their relationship. This came in many different forms, such as understanding different protocols or other ways of being in relationship. Kathy and Christine had a mutual interest in the formal arrangement of supervisor and student. Both were willing to enhance their learning through their dialogues and commitment to finding solutions to any challenges that arose. Kathy appreciated Christine's willingness to voice her concerns, express how she was making sense of things, and create space for Kathy to offer perspectives, concerns, and questions. Mentoring in this way is not about the faculty member abdicating responsibility nor unfairly burdening an Indigenous student (Pete, 2016), but a recognition that each brings wisdom to the process.

Mentorship also supports women, Indigenous and other minority groups to be successful in their careers in organizations such as higher education environments. McLeod (2012) explained that a "female leadership voice is gained through the example of role modelling, mentoring, and coaching" (p. 20). Throughout Christine's master's journey, there were other forms of Western academic activities that Kathy (along with other university faculty members) had and continue to offer in their mentorships.

In describing Māori women in leadership roles, Ndaba (2013) explained, "mentors were instrumental in the successes of the careers of the participants" (p. 202). With limited Indigenous woman scholars to lean on during her master's journey, the allyship of these non-Indigenous faculty members was appreciated by Christine in gaining hands-on experience with various academic activities. For example, Christine and Kathy, along with other faculty members, have co-presented the dual research project and co-facilitated at conference workshops. These activities were very intimidating for Christine initially, and one may argue that it can be intimidating for all new scholars to begin these academic activities. Tippeconnic Fox (2009) asserts that American Indian women still face gender bias, racism, stereotypes, discrimination, hostility, and cultural issues causing marginality and oppression at the doctoral level in higher education. For Indigenous students, particularly Indigenous women students, challenging these additional barriers while creating space within academic activities can be onerous; having mentorship eases some of the burden.

After completing the master's journey, Christine and Kathy considered how they would continue to work together. The research project provided a strong foundation for them to move forward and develop a new relationship together. As a result, Christine and Kathy have continued to attend conferences, present together, and have committed to co-publishing. This article, for example, also holds a valuable story. When first structuring the piece, Christine and Kathy's focus was on the relational aspects between Indigenous student and non-Indigenous supervisor within the graduate journey. Christine, however, felt the dissemination of the graduate work, 
as documented in the thesis as a stand-alone piece, was important to include within the article's framework. Much dialogue occurred with each expressing thoughts and feelings. Kathy agreed, albeit hesitantly. After submitting the original article, Christine reached out to Kathy. She acknowledged that some additional information could have been included that would better guide the message of the article. Upon further reflection, Christine realized that she had felt shy to publish the thesis research work on its own and included it within the original submission as a strategy to feel more comfortable engaging in this academic activity. The graduate work as a stand-alone piece was removed, and the findings interweaved within this article. Additionally, Christine learned to reframe the idea of publishing — initially an individualistic ideation to a culturally appropriate activity through the work of other Indigenous scholars. Archibald (2008) explained, "sharing what one has learned is an important Indigenous tradition" (p. 2), which is true in Nuu-chah-nulth knowledge transmission as well. Through the lived experience and the mentorship of Kathy in discussing and witnessing instead of prescribing the way to write the article, Christine accepted the lesson of publishing as a culturally appropriate activity. Christine felt empowered by the process.

One of Kathy's concerns in developing a new collegial relationship with Christine was that power over dynamics inherent in a student-supervisor relationship may linger. Mendez (2018) reminds us that power differentials include a deficit model of oppression and a strength-based model of the power of existence. Kathy struggled with concerns of not usurping the knowledge of Christine's research, or the process of their writing, in a way that Christine may feel as an academic Kathy had greater agency and decision-making around how the article took shape. After further dialogue about what would be storied, both felt assured. However, what shifted Kathy's concern about power over issues to a strength-based power of existence was when Christine reiterated what she wrote as an acknowledgement in her thesis to Kathy, namely, "walking this journey [is] a process; I appreciate your willingness to lead, follow and walk by my side" (Webster, 2019, p. 6). As a result, Christine and Kathy continue to move between leading, following and walking side by side through reciprocal mentorship.

\section{Navigating the Two-Worlds}

The burden of navigating the two-worlds can be lessened with reciprocal mentorship. The dual project research findings identified that "Indigenous students continue to experience the two-world phenomenon" (Webster, 2019, p. 62; Webster et al., 2019). This was the case for Christine, and sometimes it felt like double the work for her. Understanding Western knowledge systems while trying to apply Indigenous knowledge systems was time-consuming. Christine noted, "This required extra time throughout the inquiry ... I questioned whether or not thoughts and processes were an Indigenous way of doing things or if my academic mind was trained to do things this way" (Webster, 2019, p. 36). On a similar note, McLeod (2012) shared, "assimilative experiences caused me to question whose leadership knowledge system I was validating" (p. 19). The mentorship of Kathy fostered the ability for sense-making and understanding for Christine. As described above, Christine was cautious about interchanging Indigenous methodology practices with Western ones. Kathy and Christine talked through 
the similarities and differences between methods and referencing and not referencing them interchangeably. Although the process may present the same, the intention with which it was informed, initiated, and analyzed was different. These methods may produce what appears to be similar results; however, the approach and intention are different because the inherent worldview is different. For example, in discussing the similarities and differences between focus groups and circles, Christine and Kathy acknowledged that although these methods may appear similar because people sit in a circle and talk, in an Indigenous circle, specific protocols need to be observed. Once there was an understanding between the terminologies used, Kathy and Christine could reference the terms to help bridge the knowledge of two-worlds in which non-Indigenous people may be able to conceptualize a similar process. By referencing the terms interconnectedly, they could draw the nuances of these practices. Christine became clear that the intention underlying the use of each method was essential to understand. At other times, Christine found it a useful process to verbalize her thoughts about Kathy's different worldviews before trying to write. Kathy would listen and witness.

Navigating difference through the "other world" was not only happening for Christine but Kathy as well. Kathy gained insight into the "other world," Nuu-chah-nulth culture specifically, through her discussions and experiences with Christine. For instance, Kathy had a nonIndigenous academic colleague counsel her that for Elder gifts to be reimbursed, retail gifts would need to be purchased rather than paying for handmade gifts. When Christine explained that sometimes handmade gifts from community members are considered more intentional and perhaps more appreciated, Kathy rechecked the academic and research grant parameters of the budget to see how she could make a case for submitting receipts for handmade gifts Christine purchased (as a research assistant). Kathy couldn't find anything documented, so she submitted the receipts. Although the receipts were accepted, Kathy prepared to advocate professionally and, if necessary, reimburse the handmade gifts personally. For Christine, it was not about the financial reimbursement specifically, but the protocol generally. Through open dialogue, Kathy understood the importance of handmade gifts by local community members within "the other" world while sharing institutional perspectives and structures. The navigation of two-worlds here for Kathy was more deeply recognizing the protocols of gift-giving. In this situation, Kathy now understands that Indigenous students as community members may gift Elders differently from university faculty members outside of the community. She also learned that some Indigenous community members gift in advance of receiving knowledge, whereas others gift after receiving knowledge, and some may not practice gifting at all. The key is to seek out understanding within each particular situation and community.

Another example of experiencing the two-worlds occurred during the first term of the graduate program. Christine began the graduate journey a few months after losing her grandmother, the woman who had raised her like her own. As exemplified by others in her graduate research, Christine entered graduate school with a mindset to only focus on school; she felt she put up an emotional wall to protect her grieving process and was intent on maintaining an intellectual approach only. However, keeping an academic journey with only pieces of self was not practical nor healthy. After one reflective activities during the first term of 
the program, Christine had reached a deep emotional state that resulted in distress. Christine took to a field overlooking the ocean, with the forest lines in the periphery, and was weeping. She was questioning her decision to pursue higher education while still grieving. She silently talked to her ancestors - asking for a sign, a purpose, an understanding of what it was she was called to do. She was looking for justification, assurance, something - anything to stay in school or quit. She put her hand over her heart, where the eagle pendant that her grandmother gave her was positioned and continued to sob uncontrollably. Suddenly, overhead were two eagles soaring. In Nuu-chah-nulth beliefs, timely appearances from majestic creatures are considered visits from loved ones who have joined the ancestors in the spirit world. A calming warmth flowed through her body as she received the sign for which she was asking. This was the Nuu-chah-nulth concept of heshook-ish tsawalk: everything is one (Atleo, 2004). Relying on her Nuu-chah-nulth teachings helped ground her in that moment of her educational path; Christine felt that she was exactly where she was meant to be, experiencing exactly what was meant to be experienced, and her conviction to continue her journey in the academic world was strengthened.

Further to this experience was the critical dialogue that emerged between Christine and Kathy. Kathy explained that the intention behind the activity Christine experienced was to challenge students to look deeply within and find connections with self, others, and nature. Kathy shared that in a program that seeks to support students to transform their self and world views, students can experience different emotional reactions, and this is anticipated. In the particular activity that distressed Christine, Kathy found that for both Indigenous and non-Indigenous students, the activity tended to evoke a deep emotional and transformative experience. Christine explained that although that may be true, for her and perhaps for other Indigenous students the experience goes beyond - touching deep into the historical experiences Indigenous peoples have suffered within academic institutions. Christine shared that in the activity her first reaction was to disengage from the process altogether; to quit. Christine reminded Kathy of the mistrust Indigenous peoples have with academic institutions, and while other non-Indigenous students may experience an emotional reaction, their first response may not be to quit. She counselled that instructors must also navigate the two-worlds by understanding the reasoning behind Indigenous students' actions and reactions and the historical experiences of Indigenous peoples to support Indigenous students truly. Kathy had had a previous interaction with an Indigenous student who had the reverse experience, confiding in Kathy that she was about to quit the program as she was unsure of her place in the academy but after the experience realized she was in the right place. With Christine's wisdom sharing, Kathy realized that there were fundamental core impacts from the different worlds to consider when designing and facilitating certain activities.

Christine and Kathy's experience confirmed the finding that "Indigenous students developed positive relationships with instructors and cohort; however, identified opportunities for instructor preparedness" (Webster, 2019, p. 62; Webster et al., 2019). One recommendation offered was to incorporate a cleansing practice, such as cedar brushing, after conducting deep, reflective activities to ensure all students, Indigenous and non-Indigenous, leave the activities 
free from potential negativity but with good minds and hearts as the activity intended. However, integrating this type of content requires instructors to understand the history and connect with Indigenous knowledge keepers to provide guidance. In doing so, reciprocal mentorship can ripple out beyond student and instructor to local Indigenous community members and nonIndigenous students and faculty of the academic community.

Engaging in reciprocal mentorship, Christine and Kathy found that as each brought their specialized knowledge in one of the two-worlds - Kathy in academia and Christine in Indigenous perspective - better impacts could be found across both worlds. Similarly, Liang and Peters-Hawkins (2017) found that the participants in their study "'embraced' good values from both [Asian and American] cultures" (p. 60). Furthermore, Chilisa (2016) reminds us, "an Indigenous Research Methodology is not exclusive of other knowledge systems ...because if it does it loses the value, our value as Indigenous peoples, as First Nations, as African people, our values of embracing others" [33:33]. Christine prioritized Nuu-chah-nulth perspective; however, she acknowledged influences of both worlds.

\section{Finding a Common Language}

Communication was a vital element in the reciprocal mentorship relationship. Within Christine and Kathy's student-supervisor relationship, they engaged in many forms of contact: email, phone, video conferencing, and in-person meetings. Establishing a common language was often derived from particular word usage, the intention of the word choices, and the underlying interpretation of words from lived experience. Finding a common language to understand each other's perspective was another form of trans-systemic knowledge in action. This pathway allowed for open dialogue, thus minimizing misinterpretation. Themes that contributed to our discussion included: Nuu-chah-nulth words used to express particular experiences; alternative English words used in place of research words customarily found in academia; and other intuitive communication forms.

Nuu-chah-nulth words are not a new language, quite the contrary, Nuu-chah-nulth is an ancient language. However, using Nuu-chah-nulth words in academic contexts is relatively new. For example, Nuu-chah-nulth scholar Atleo (2004) introduced the Nuu-chah-nulth word oosomich as methodology as "an acknowledgment of the cognitive limitations of the physical domain" (p. 124). As a Nuu-chah-nulth woman, Christine understood this work as an expression of translation, selecting a Nuu-chah-nulth word that was better suited toward its intention and use in Western contexts.

For Christine, using Nuu-chah-nulth words to better describe feelings and experiences began during her master's degree coursework. For example, there was a phrase used throughout the program delivery of "trusting the process." This phrase was not new language from Christine's perspective; its use was familiar in other outlets. However, asking an Indigenous student to trust the process in higher education, given the history of educational systems used negatively toward Indigenous peoples, felt like a challenge and a misalignment for Christine. As described earlier, during a reflective exercise when students are challenged on multiple levels intellectually, emotionally, physically, and spiritually, the Nuu-chah-nulth phrase heshook- 
ish tsawalk: everything is one (Atleo, 2004) provided comfort to Christine. At that moment, she was guided to trust that everything is one and this experience paralleled trusting the process. Similar experiences were shared by Indigenous students in the one-on-one discussions (interviews) during the research project, although they used word equivalents from their Indigenous languages. For Kathy, connections were made to different Western literature such as systems thinking (Cabrera \& Cabrera, 2015; Scharmer \& Kaufer, 2013) and systems being (Laszlo, 2012) that recognizes the inter-relationality of everything.

Another example of Nuu-chah-nulth expression described an internal process Christine experienced within the research journey. During the research journey, Christine confronted the feeling of needing to compare or validate against Western practice. Smith (2012) reminded, "Methodology is important because it frames the questions being asked, determines the set of instruments and methods to be employed, and shapes the analyses" (p. 144). This message reminded Christine to pay attention to all the sensory experiences as knowledge was being gathered, specifically mindful to what she described as her thli-mubk-sti, or internal pauses. Atleo (2004) defined thli-muhk-sti as "every life form is of one thli-muhk-sti (spirit)" (p. 61), and Christine also understood this to be as the spirit within each individual, the innermost feeling of our being where teachings are treasured and protected. tli-muhk-sti guides one from right and wrong, and the way to walk the earth with integrity. In a Western context, the internal pauses may be thought of as intuition. Using thli-muhk-sti in place of internal pauses or intuition brought a deeper level of understanding for Christine within the methodology and intention supported by Nuu-chah-nulth values.

Dialoguing about thli-muhk-sti and other Nuu-chah-nulth words used to express particular situations and experiences, Christine and Kathy delved into deeper levels of conversation. These conversations supported the whole person learning — intellectually, emotionally, physically, and spiritually by clarifying the similarities and differences in views. This also laid the foundations for Christine to utilize alternative English words in place of research words customarily found in academia.

Utilizing English words in place of academic research words enabled Christine to align with the intention and interpretation of the research project. Smith (2012) explained, "The word itself, 'research,' is probably one of the dirtiest words in the [I]ndigenous world's vocabulary" (p. 1). Research for Indigenous communities represents the extraction of knowledge without consent or benefit to the community, extraction by Western context research. Absolon (2011) presented her work as "a petal flower with roots (worldview), centre flower (self), leaves (journey), stem (analytical backbone) and petals (methods)" (p. 12). Inspired by Absolon (2011), Christine also chose to use alternative English words in place of academic research terminology. For example, knowledge gathering (data collection) methods, knowledge sharing providers (participants), sense-making (data analysis), offered guidance (recommendations), or, as noted above, oneon-one discussions (interviews), among others. Kathy appreciated and encouraged Christine's integrity and desire to reflect the research accurately from an Indigenous worldview. Christine was interested to learn that Kathy, in her doctoral work, had also suggested alternative language (see Bishop, 2015). Through the trans-systemic worldviews of theatre and research, Kathy 
found that research terminology was privileged over theatre terminology and therefore sought to acknowledge and value theatre's worldview when doing theatre-based research.

As Christine and Kathy's journey evolved, finding a common language came through not only using Nuu-chah-nulth words or alternative English words; it was through other forms of communication. Storytelling is often how Christine communicated her way through the imbalances that Indigenous and Western processes created to express how she was feeling. Storying did take more time, but time was important to take so that Christine felt that Kathy truly understood Christine's experiences. However, when Christine was hesitant to speak, usually through the silent awkwardness, Kathy could sense this. Often the silent awkwardness resulted from an imbalance of understanding perspectives, a misinterpretation of "cringe" words or themes that held different meanings within the different knowledge systems. Silent awkwardness was a response that resulted from Christine trying to formulate an appropriate, respectful response. Respectfully, Kathy would ask what was going on for Christine, knowing intuitively that more internal processing occurred. If the awkward silence could be talked through, it would be. If it couldn't be, this is when Christine would later use alternative forms of communication, such as email, to share with Kathy in a manner that provided space to process the imbalance and to share her thoughts cohesively. No matter which communication form was used, the heart of finding a common language was sense-making together. Sensemaking was foundational to navigating the two-worlds, as was having shared values.

\section{Having Shared Values}

Reciprocal mentorship is developed and enhanced through shared values. Christine and Kathy formed a mutual mentoring relationship by honouring their core values, such as respect, curiosity, and integrity, among others. Respect was demonstrated in a number of ways: 1) the methods that were used to communicate, 2) the respect each had for contradictory protocols, and 3) the respect for each other as life-beings. Curiosity was also managed respectfully. When either felt curious about academic or cultural protocols, respectful dialogue took place. Integrity was important for both Christine and Kathy: the integrity of the research community and methodology and the integrity of the academic requirements for completing a degree. Personal integrity was held in high regard, as it was with personal integrity that Christine and Kathy were able to observe, experience and reflect on the trans-system knowledge transfer. Furthermore, Christine and Kathy shared a deep commitment to family and the importance of education and responsibility to give back to the community.

Reciprocal mentorship also felt similar to Wilson's (2008) depiction of relational accountability. He articulated, "Relational accountability requires me to form reciprocal and respectful relationships within the communities where I am conducting research" (p. 40). While reciprocal relationships need to be formed within the community of research, it is also important for a reciprocal relationship to be formed between student and supervisor. Liang and Peters-Hawkins (2017) described, "mentorship depended more on shared beliefs and to a less extent compatible personalities" (p. 55). Christine and Kathy each brought their core values to their student-supervisor relationship and discovered many shared values between them. 
Having shared values extended beyond the student-supervisor relationship into relationship with community and environment; we are all one, after all. The university funded a research project committed to understanding how the overall learning experience for Indigenous students could be enhanced. In return, Indigenous students offered guidance. One recommendation was for the university community to "cocreate a 'Walk of the Lands' with and by the local Indigenous communities to story the land usage pre-colonization" (Webster, 2019, p. 103; Webster et al., 2019). In this way, values of respect, curiosity and integrity can be furthered, along with collaboration. Collaboration between academic units and Indigenous student support departments connects Indigenous students and university community members in direct engagement with Indigenous peoples and Indigenous places. Having these experiential activities available allows Indigenous students to connect to their own ways of knowing, being and doing, and university community members to engage in relationships with the local Indigenous communities and lands. Thus, advancing a trans-systemic environment for both Indigenous and Western worldviews.

\section{Moving Forward on the Journey}

Kovach (2009) encouraged a way of "giving back to community ... [is] by sharing our work so that it can assist others" (p. 11). It is the hope of the authors that through the sharing of our story, Indigenous and non-Indigenous students and supervisors can see themselves within the stories and seek the way of reciprocal mentorship to navigate two-worlds, find a common language, and build upon shared values to not only be successful in the academic research and educational journey, but make an impact in their university and beyond.

Misunderstanding of Indigenous students within the academy, and Indigenous people in general, will continue if there are no change initiatives by academic institutions, such as is being initiated and supported by Royal Road University both intentionally and emergent as happened with reciprocal mentorship. Battiste (2014) noted the first wave of the Indigenous renaissance agenda was "to transform the status quo of educational curricula to more effectively include IK" (p. 91). The second wave "has involved convincing governments and institutions, as well as our own peoples, to acknowledge the unique knowledge and relationships that Indigenous peoples derive from place and from homeland" (p. 93). Perhaps, the third wave will include reciprocal mentorship. Kuokkanen (2007) called for a new relationship between the academy and Indigenous people that utilizes a new paradigm based on the logic of gift; "The logic of gift foregrounds a new relationship — one that is characterized by reciprocity and by a call of responsibility to the 'other"' (p. 2). The work to find ways of inclusion, honouring people, language and stories, and enabling Indigenous students to bring their whole selves into the academy will have exponential benefits to Indigenous students, Indigenous communities, academic institutions, and society. In this way, students and faculty could dream a new world into reality, one in which the strength of Indigenous knowledge and values can coexist and intermingle in a healthier and mutually beneficial way and that will be honoured and respected by all Indigenous and non-Indigenous Canadians. 


\section{About the Authors}

Christine Webster is a Nuu-chah-nulth woman from the Ahousaht Nation. She recently completed the Master of Arts in Leadership degree from Royal Roads University and is a doctoral student at the University of Victoria. Webster's current interest is in exploring Indigenous leadership and Indigenous-non-Indigenous relationships in higher education.

Kathy Bishop (corresponding author) is a Scottish and European descent woman, an academic supervisor, and an associate professor and MA Leadership program head at Royal Roads University. She received her Doctor of Philosophy in Interdisciplinary studies. She is a passionate scholar-practitioner who has published on collaborative leadership, ethics, creativity, and action-oriented research. Email: kathy.bishop@royalroads.ca

\section{References}

Absolon, K. (2011). Kaandossiwin: How we come to know. Fernwood Publishing.

Archibald, J. (2008). Indigenous storywork: Educating the heart, mind, body, and spirit. UBC Press. Atleo, E. R. (2004). Tsawalk. UBC Press.

Battiste, M. (2010). Indigenous knowledge and Indigenous peoples' education. In Subramanian, S. M., \& Pisupati, B. (Eds.), Traditional knowledge in policy and practice: Approaches to development and human well-being (pp. 31-51). United Nations University Press.

Battiste, M. (2014). Ambidextrous epistemologies: Indigenous knowledge within the Indigenous renaissance. In Kamboureli, S., Verduyn, C., \& Canadian Electronic Library (Eds.), Critical collaborations: Indigeneity, diaspora, and ecology in Canadian literary studies (pp. 83-98). Wilfrid Laurier University Press.

Bessette, L. S. (2015). Reciprocal mentoring: Rethinking the traditional model. Women in Higher Education, 24(1), 18-19. https://doi.org/10.1002/whe.20158

Bishop, K. (2015) Spinning red yarn(s): Being artist, researcher, educator through playbuilding as qualitative research. [Doctoral dissertation]. University of Victoria.

Retrieved from https://dspace.library.uvic.ca/handle/1828/5853

Cabrera, D., \& Cabrera, L. (2015). Systems thinking made simple (2nd ed.). Plectica Publishing.

Chilisa, B. (2016, February). Equity in diversity: Indigenous research methodologies [video]. YouTube. https://www.youtube.com/watch?v=B-SYnx8kRFU

Desai, S., Rao, S. A. \& Jabeen, S. S. (2018). Developing cultural intelligence: Learning together with reciprocal mentoring. Human Resource Management International Digest, 26(3), 38-40. https://doi.org/10.1108/HRMID-03-2018-0050

Ferguson, S. (2017). Ask not what your mentor can do for you...: The role of reciprocal exchange in maintaining student-teacher mentorships. Sociological Forum, 33(1), 211-233. https://doi.org/10.1111/socf.12406 
Glesne, C. (2016). Becoming qualitative researchers: An introduction (5th ed.). Pearson.

Harvey, M., McIntyre, N., Thompson Heames, J. \& Moeller, M. (2009). Mentoring global female managers in the global marketplace: Traditional, reverse, and reciprocal mentoring. International Journal of Human Resource Management, 20(6), 1344-1361. https://doi.org/10.1080/09585190902909863

Kovach, M. (2009). Indigenous methodologies: Characteristics, conversations and contexts. University of Toronto Press.

Kram, K. (1985). Mentoring at work: Developmental relationships in organisational life. Scott, Foresman and Company.

Kram, K. E. \& Hall, D. T. (1997). Mentoring in a context of diversity and turbulence. In Kossek, S. \& Lobels, L. (Eds.), Management diversity: Human resource strategies for transforming organizations. (pp. 108-136). Blackwell.

Kuokkanen, R. J. (2007). Reshaping the university: Responsibility, Indigenous epistemes, and the logic of the gift. UBC Press.

Laszlo, K. (2012). From systems thinking to systems being: The embodiment of evolutionary leadership. Journal of Organisational Transformation \& Social Change, 9(2), 95-108.

Liang, J. \& Peters-Hawkins, A. (2017). "I am more than what I look alike”: Asian American women in public school administration. Educational Administration Quarterly, 53(1), 40-69.

McLeod, Y. (2012). Learning to lead kokum style: An intergenerational story of eight First Nations women. In C. Kenny \& T. Ngaroimata Fraser (Eds.), Living Indigenous leadership: Native narratives on building strong communities (pp. 17-47). UBC Press.

Marker, M. (2016). Indigenous knowledge, indigenous scholars, and narrating scientific selves: “To produce a human being." Cultural Studies of Science Education, 11(2), 477-480. https://doi.org/10.1007/s11422-015-9660-1

Mendez, M. (2018). "The river told me": Rethinking intersectionality from the world of Berta Caceres. Capitalism Nature Socialism, 29(1), 7-24.

Ndaba, Z. (2013). Māri women moving into leadership roles: A New Zealand perspective. Proceedings of the European Conference on Management, Leadership \& Governance, (pp. 198-204).

Pidgeon, M., Archibald, J. \& Hawkey, C. (2014). Relationships matter: Supporting Aboriginal graduate students in British Columbia, Canada. Canadian Journal of Higher Education, $44(1), 1-21$.

Pete, S. (2016). 100 ways: Indigenizing and decolonizing academic programs. Aboriginal Policy Studies, 6(1), 81-89. https://dx.doi.org/10.5663/aps.v6i1.27455

Saldaña, J. \& Omasta, M. (2018). Qualitative research: Analyzing life. Sage.

Scharmer, O. \& Kaufer, K. (2013). Leading from the emerging future: From ego-system to eco-system economies. Berrett-Koehler Publishers.

Smith, L. T. (2012). Decolonizing methodologies: Research and Indigenous peoples (2nd ed.). Zed Books.

Tippeconnic Fox, M. J. (2009). American Indian women in higher education: Navigating the doctorate. Studies in the Humanities, 36(2), 69-76.

Thomas, R. A. (2018). Protecting the sacred cycle: Indigenous women and leadership. JCharlton Publishing.

Truth and Reconciliation Commission of Canada. (2015). Honouring the truth, reconciling for the future: Summary of the final report of the Truth and Reconciliation Commission of Canada. http://nctr.ca/assets/reports/Final\%20Reports/Executive_Summary_English_Web.pdf 
Webster, C. (2019). Traversing Culture and Academy [MA. Leadership Thesis]. Royal Roads University. Retrieved from https://viurrspace.ca/handle/10613/12811

Webster, C., Bishop, K., Krause, W. \& Hartney, E. (2019). Buttedahl Skene Fund: Indigenous Alumni Survey (IAS) Final Report (BSF 18-02). Royal Roads University.

Wilson, S. (2008). Research is ceremony. Fernwood. 